\title{
Meteorological Drought Events and Their Evolution from 1960 to 2015 Using the Daily SWAP Index in Chongqing, China
}

\author{
Bo Liu ${ }^{1}$, Yubing Liu ${ }^{1}$, Wenpeng Wang ${ }^{1, *}$ and Chunlei $\mathrm{Li}^{2}$ \\ 1 College of Hydrology and Water Resources, Hohai University, Nanjing 210098, China; \\ bobol3705@163.com (B.L.); lybowie@hhu.edu.cn (Y.L.) \\ 2 Chongqing Hydrological Center, Chongqing 401120, China; lichunlei_cq@163.com \\ * Correspondence: wangwenpeng@hhu.edu.cn
}

Citation: Liu, B.; Liu, Y.; Wang, W.; Li, C. Meteorological Drought Events and Their Evolution from 1960 to 2015 Using the Daily SWAP Index in Chongqing, China. Water 2021, 13, 1887. https://doi.org/10.3390/ w13141887

Academic Editors: Renata J. Romanowicz and Wen Wang

Received: 31 May 2021

Accepted: 5 July 2021

Published: 7 July 2021

Publisher's Note: MDPI stays neutral with regard to jurisdictional claims in published maps and institutional affiliations.

Copyright: (c) 2021 by the authors. Licensee MDPI, Basel, Switzerland. This article is an open access article distributed under the terms and conditions of the Creative Commons Attribution (CC BY) license (https:/ / creativecommons.org/licenses/by/ $4.0 /)$.
Abstract: Meteorological droughts are natural disasters that have been linked to economic losses and casualties. Decision-makers need to understand the temporal and spatial variation of meteorological drought events at a daily to weekly scale to develop a more elaborate framework for drought risk management. The present study used the standardized weighted average of precipitation index (SWAP) as an indicator of meteorological droughts, computed from the daily precipitation dataset (1960-2015) of 34 meteorological stations in Chongqing, China. The multi-threshold run theory was applied to identify drought events. Variation of drought characteristics was estimated by the modified Sen's trend test. The results suggested the following findings: (1) the onset, duration, and severity of drought events identified by the SWAP index are in good agreement with the real local records; (2) there was no significant linear trend and abrupt change in annual duration and severity of drought events, but the decadal variation was obvious. From a decadal perspective, the annual frequency, duration, and severity of drought events showed a steady decreasing trend before the 1990s, and then fluctuated upward; (3) the spatial variation of the duration and severity of ordinary drought events was quite inconsistent at different periods. The annual drought days and severity increased from 1960 to 2015 but decreased after 1990. From 1960 to 2015, the duration days and severity of persistent, long persistent, severe, and extreme drought events declined insignificantly in most parts of the middle and southeast regions but increased in the western and northeast regions. The drought situation in Chongqing shows a large range of variation and obvious spatial heterogeneity. The SWAP index is an effective tool to identify the evolution of daily scale meteorological drought events.

Keywords: SWAP index; drought events; Sen's trend test; Pettitt test; spatiotemporal dynamics of reginal drought; Chongqing

\section{Introduction}

Drought events mainly have a negative impact on daily life, economic development, and water environment. Generally, droughts can be divided into meteorological, hydrological, agricultural, and socio-economic drought [1-3]. Meteorological drought, associated with insufficient precipitation, usually triggers other types of droughts. Changes in the frequency, severity, and duration of drought events reflect the impact of drought disaster. Drought impact will aggravate if the magnitude of drought increases, or the recovery time between severe drought episodes shortens [4].

During the past few decades, many efforts have been made to monitor and characterize droughts. The Palmer drought index (PDSI) [5], the standardized precipitation index (SPI) [6], the standardized precipitation evapotranspiration index (SPEI) [7] as well as the China-Z index (CZI) [8] have been put forward to promote the meteorological drought research and track the effect of meteorological drought on stream flow [9]. PDSI and SPI have been frequently used around the world. However, the deficiencies of the PDSI and SPI are obvious in calculating over a short time scale (daily or weekly). These annually or 
monthly based indexes usually fail to extract drought events across months or sharp turns between flood and drought. Therefore, some short time-scale indexes have been proposed, such as the effective drought index (EDI), the weighted average of precipitation index (WAP) and the standardized weighted average of precipitation index (SWAP). By applying a weighting function to daily rainfall data, EDI has been utilized to detect and quantify drought events in many countries, including Korea, Iran, Kenya, and Australia [10-13]. The typical calculation of EDI of a specific day considers the precipitation of 364 days before that day. If the current situation of drought is only determined by the recent precipitation nor by the previous one-year precipitation, the EDI would misidentify the drought event. The WAP, proposed by $\mathrm{Lu}$ in 2009, was applied to determine the start dates, duration, and strength of the drought over the Mississippi River basin [14]. Then, the SWAP was developed to detect the regional atmospheric anomalies causing the 2009-2010 drought in China, which proved that SWAP can identify the onset, duration, and severity of droughts reliably $[15,16]$. The number of previous daily data required to calculate the WAP and SWAP can be set according to actual drought situations. Furthermore, the SWAP had good applications in the identification and characteristic analysis of droughts in the central China [17].

The drought indexes, based on prior research, were frequently proposed to characterize long-term droughts and are rarely applied on a daily scale. However, it is crucial for decision-makers to capture drought events promptly and to monitor drought situations properly. Especially for the frequent cross-month droughts and sharp turns between flood and drought in Chongqing, the monthly scale drought index does not give a clear definition of the specific onset and other prosperities of drought events. Few studies analyzed the spatiotemporal dynamics of drought in Chongqing on a daily scale. The SWAP index can identify the occurrence, duration, and severity of drought. It can help to analyze the drought situation appropriately. Chongqing is a mountainous area. The concentration time of mountainous rivers is generally short. The meteorological drought and hydrological drought have good synchronization. Therefore, the study selected meteorological drought as the research object that can effectively describe the drought situation in Chongqing. Specifically, we used the SWAP to extract the drought events and analyze the variation of drought characteristics to promote the understanding of daily scale droughts in Chongqing.

This study aims at analyzing the spatiotemporal dynamics of drought in Chongqing based on the drought index from 1960 to 2015. The structures of this paper are as follows: (1) to discuss the applicability of the daily index SWAP to drought identification; (2) to extract and characterize the drought events by the multi-threshold run theory; (3) to analyze drought variation by the modified Sen's trend test. The findings would expect to provide decision-making references for predicting drought events and formulating drought relief plans in Chongqing, China.

\section{Study Area and Data}

Chongqing, located at $28^{\circ} 10^{\prime}-32^{\circ} 13^{\prime} \mathrm{N}$ and $105^{\circ} 17^{\prime}-110^{\circ} 11^{\prime} \mathrm{E}$, with an area of $82,400 \mathrm{~km}^{2}$, is the only municipality in southwest China. The climate is humid with an annual precipitation ranging from $1000 \mathrm{~mm}$ to $1350 \mathrm{~mm}$. However, the intra-annual precipitation is rather uneven as a result of the subtropical monsoon system, mainly concentrated in the rainy season from May to September. The region has many kinds of geographical terrain, including high mountains, plateaus, the Yangtze River, the reservoir area of the Three Gorges Project, megacities, and several rural areas. The complex landform affects local atmospheric circulation, yielding variable weather. Even in the rainy season, drought events may happen on a daily time scale.

The daily SWAP index is calculated on the basis of daily precipitation data (1960-2015). The data was recorded from 34 meteorological stations in Chongqing and has been effectively quality controlled and complied by the National Climate Center of the China Meteorological Administration [18]. The locations of meteorological stations are presented in Figure 1. 


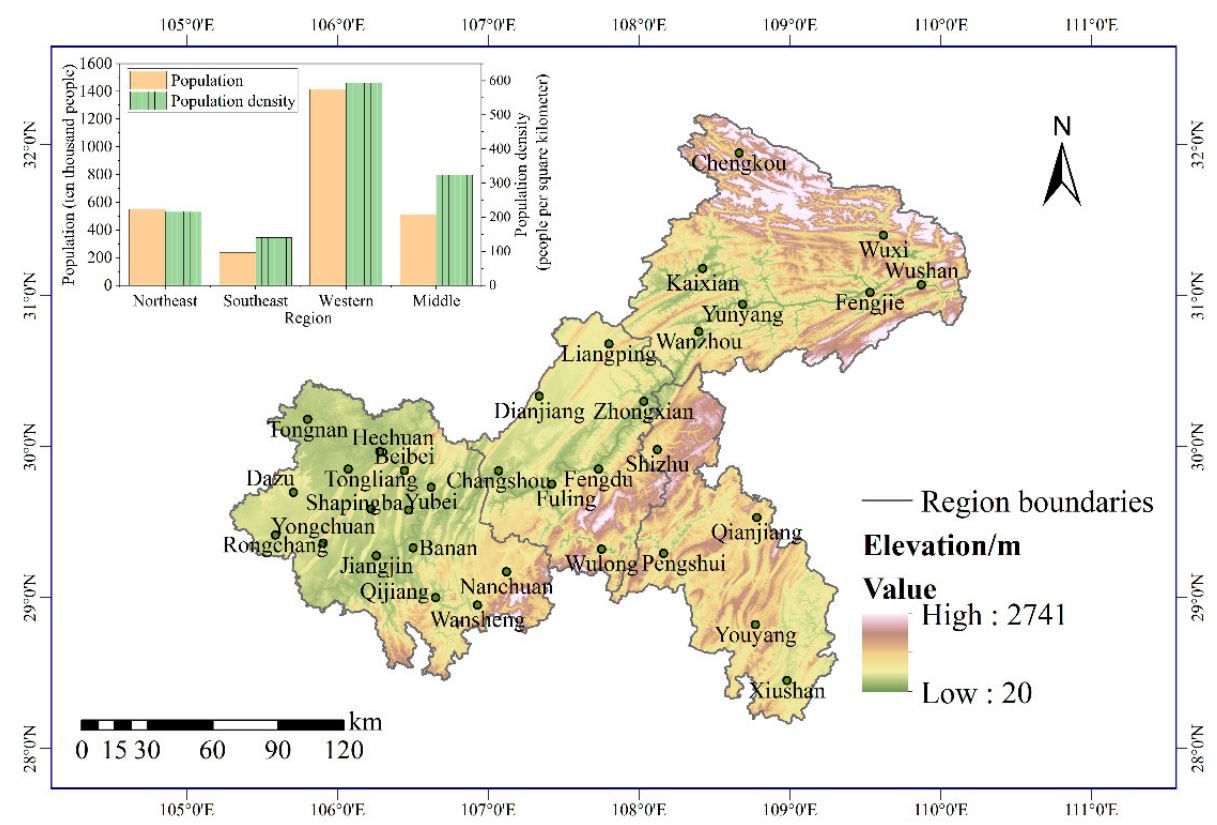

Figure 1. The Chongqing area and the distribution of meteorological stations.

\section{Methodology}

\subsection{Standardized Weighted Average of Precipitation Index (SWAP)}

The weighted average of precipitation index (WAP) was derived from a physically based conceptual model [14]. The WAP characterizes the current drought situation according to the current precipitation and the cumulative decay effects of the previous precipitation. The SWAP is the standardized WAP index [15].

The mathematical form of WAP is written by:

$$
\begin{aligned}
& W A P=\sum_{n=0}^{N} \omega_{n} P_{n} \\
& \omega_{n}=(1-a) \times a^{n}
\end{aligned}
$$

where $P_{n}$ denotes the daily precipitation that happens $n$ days earlier, $N$ is the number of previous daily data required to calculate the daily WAP, $a \in(0,1)$ is a parameter that determines the weight $\omega_{n}$, which measures the contribution of earlier precipitation on the current extent of drought. The higher the $\omega_{n}$ is, the more contribution of an earlier precipitation on the current drought state. Theoretically, the precise calculation of the WAP index requires infinite previous precipitation data. However, for practical application, an $a$ of 0.9 and $N$ of 44 are suggested for the estimation of WAP by taking the truncation precision as $1 \%$ [14].

In this way, the WAP values were calculated for each day by the use of precipitation data of the previous 44 days. The standardized WAP (SWAP) can be obtained by converting the probability distribution of WAP into a standard normal distribution. The SWAP is the normal variate that has an equivalent cumulative probability with that of the WAP in its original distribution. As the WAP is a linear combination of precipitation that empirically follows gamma distribution, we may estimate the SWAP through solving the following equation.

$$
\frac{1}{\sqrt{2 \pi}} \int_{-\infty}^{\text {SWAP }} e^{-Z^{2} / 2} d Z=\frac{1}{\beta^{\gamma} \Gamma(\gamma)} \int_{0}^{\text {WAP }} x^{\gamma-1} e^{-x / \beta} d x
$$


where the scale parameter $\beta$ and shape parameter $\gamma$ of the $\Gamma$ distribution are both greater than zero. The SWAP thresholds corresponding to various drought grades are depicted in Table 1.

Table 1. Classifications of SWAP drought grade.

\begin{tabular}{ccc}
\hline Grade & Type & SWAP Threshold \\
\hline 1 & Non-drought & $-0.5<$ SWAP \\
2 & Mild drought & $-1.0<$ SWAP $\leq-0.5$ \\
3 & Moderate drought & $-1.5<$ SWAP $\leq-1.0$ \\
4 & Severe drought & $-2.0<$ SWAP $\leq-1.5$ \\
5 & Extreme drought & SWAP $\leq-2.0$ \\
\hline
\end{tabular}

\subsection{Drought Identification and Characterization}

Meteorological drought is defined as a condition of insufficient precipitation for a period of time. Drought events can be obtained by setting thresholds on the SWAP series according to the run theory. The run theory has been widely used in screening drought events to determine their duration and severity, the time of onset and termination [19-22].

Following the method recommended by Zhao, Y. et al. [17] and considering the actual drought situation in Chongqing, we implemented the procedure of drought event identification as follows:

(1) When SWAP values are lower than -1 for at least seven consecutive days (lower limit of a mild drought), a drought event starts. The initial date is the first day of these seven days.

(2) When SWAP values are higher than 0.5 for at least three consecutive days (upper limit of normal state), the drought event ends. If SWAP exceeds 0.5 , a humid event is recorded. The end date is the last day of these three days.

(3) Drought duration is the time interval from the initial date to the end date of a drought event.

(4) Drought severity is the sum of the absolute values of SWAP that is lower than -1 in a drought event.

Drought events can be divided into two categories according to the duration and magnitude (Table 2). Firstly, we divide drought events into ordinary drought, persistent drought and long persistent drought based on the duration. While the SWAP index is lower than -1 for more than seven days, 14 days, and 21 days, an ordinary drought, persistent drought, and long persistent drought event begins, respectively. The above three drought events end when SWAP is higher than 0.5 for more than three days, six days and nine days, respectively. Secondly, we divide drought events into ordinary, severe, and extreme droughts based on the magnitude. When the SWAP index is lower than $-1,-1.5$, and -2 for seven days, an ordinary drought, severe drought, and extreme drought event starts, respectively. Their end conditions are that the SWAP exceeds 0.5 for at least three consecutive days. The initial date of a drought event is the first day that is lower than -1 , -1.5 , and -2 . The end date is the third day that is higher than 0.5 for more than three days.

According to the above definition, the shortest duration of an ordinary drought event, persistent drought event, and long persistent drought event are 10 days, 20 days, and 30 days, respectively. The shortest period of a severe and extreme drought event are 10 days. The 10-day scale is in agreement with the real drought records in Chongqing [23]. Hence, this localized definition is beneficial for identifying the real drought events that have practical implications on drought management.

To investigate the temporal evolution of drought events, we identified drought events at each meteorological station, and then evaluated their temporal variation by the use of three regional characteristics. The annual duration is the total drought duration within a specific year on multi-site average. The annual severity is the sum of severity within a year on the multi-site average. The annual frequency is the total number of drought events occurring at all the stations within a specific year. The temporal means of annual duration, 
severity, and frequency from 1960 to 2015 are their multi-year averages, respectively. The temporal trends of the drought duration and severity were also analyzed at each station, and then the trend statistics were spatially interpolated over the study area.

Table 2. Definition of five types of drought events.

\begin{tabular}{cccc}
\hline Types & Characterization & Start Condition of SWAP & End Condition of SWAP \\
\hline ordinary & short duration and low magnitude & $<-1$ for seven days & $>0.5$ for three days \\
persistent & long duration and low magnitude & $<-1$ for 14 days & $>0.5$ for six days \\
long persistent & very long duration and low magnitude & $<-1$ for 21 days & $>0.5$ for nine days \\
severe & short duration but high magnitude & $<-1.5$ for seven days & $>0.5$ for three days \\
extreme & short duration but very high magnitude & $<-2$ for seven days & $>0.5$ for three days \\
\hline
\end{tabular}

\subsection{Statistical Analysis of Temporal Changes}

Modified Sen's Trend Test

In the classic trend assessment, many assumptions on hydrological data are necessary, such as serial independence, homoscedasticity, and normal probability distribution [24]. To release these strict assumptions, Sen proposed an innovative trend analysis method $[25,26]$ that introduces a new trend plot to display trend characteristics within the time sequence. The method divides a complete time series into two equal sub-series and then sorts each sub-series into ascending order [27]. The trend slope estimate is computed by:

$$
S=\frac{2\left(\overline{y_{2}}-\overline{y_{1}}\right)}{n}
$$

where $y_{1}$ is the average of the previous sub-series; $y_{2}$ is the average of the later sub-series; $n$ is the number of all the data points.

Wang et al. [28] found deficiencies in the slope variance proposed by Sen [24]. After correcting the original formula, the slope variance estimator and the trend test statistic have the following expressions:

$$
\begin{aligned}
& V_{o}(S)=\frac{16 \sigma^{2}}{n^{3}} \\
& Z_{S}=\frac{S}{\sqrt{V_{0}(S)}}
\end{aligned}
$$

where $\sigma$ is the standard deviation of the complete time series. The trend test statistic (Equation (6)) is suitable for trend analysis on time-independent data.

The Pettitt test

The Pettitt test is a non-parametric test for change point detection [29]. The test is free of data distribution. Its principle is to check every candidate division points with estimated probabilities. The point with the highest probability is determined to be the most probable change point. If the estimated probability exceeds the pre-assigned confidence level, then the selected change point is statistically significant. The Pettitt test has been widely used to detect change points in hydrological timeseries [30].

In this study, we applied the modified Sen's trend test and the Pettitt test to verify whether or not the duration and severity of drought events have exhibited significant changes.

\section{Results and Discussion}

\subsection{Capability of SWAP Index on Drought Event Identification}

Drought events in Chongqing from 1960 to 2015 were extracted based on the SWAP index and the run theory. To evaluate the screening capability of the SWAP index for drought identification, some typical drought events were selected from historical records as references [23]. We also extracted drought events by the use of SPI index for comparison. 
In general, drought events identified by SWAP were more consistent with historical records than that of the SPI index.

As shown in Table 3, the SWAP index acquires the ability to identify cross-month drought events. This task is apparently undone via the monthly SPI index. For example, in 1961, a drought event identified on SWAP showed a severe summer drought lasting for 67 days from June in the Yunyang district. This drought was documented in the historical record. SPI only identified drought in June and July but missed the August drought. In 1966, SWAP showed a mid-summer drought in the Bishan district. This drought lasted for 39 days from 16 July to 23 August, which was also consistent with the historical record. However, SPI missed the August drought event. In 1971, SWAP identified a long persistent drought from July to early October in the Xiushan district. SPI cannot account for the impact of former drought occurring in July and August; therefore, it regarded the precipitation state in September as normal. In 1975, the recorded winter drought in the Chengkou district was identified by SWAP, but not by SPI. In 1985, the recorded long persistent midsummer and autumn drought in the Fengdu district can be identified by SWAP. SPI lost the long duration of this drought event because the extent of drought alleviated in August. Similar cases occurred in 1990 and 1997; both the mid-summer and autumn drought in the Changshou district and the winter drought in the Shapingba district can be identified by SWAP. However, SPI failed to track these droughts until their endings.

Table 3. Identification of typical drought events and the corresponding historical records in Chongqing during from 1960 to 2015.

\begin{tabular}{|c|c|c|c|c|c|}
\hline Station Name & Start Date * & End Date * & $\begin{array}{l}\text { Duration } \\
\text { (Days) * }\end{array}$ & Historical Records & $\begin{array}{l}\text { Identified Events } \\
\text { Based on SPI }\end{array}$ \\
\hline Yunyang & 14 June 1961 & 19 August 1961 & 67 & $\begin{array}{l}\text { The severe summer drought lasted } \\
\text { for about } 80 \text { days from June. }\end{array}$ & $\begin{array}{l}\text { Extreme in June, mild in July } \\
\text { and normal in August }\end{array}$ \\
\hline Bishan & 16 July 1966 & 23 August 1966 & 39 & $\begin{array}{l}\text { The mid-summer drought lasted for } \\
30 \text { days from } 12 \text { July to } 10 \text { August. }\end{array}$ & $\begin{array}{l}\text { Moderate in July and normal } \\
\text { in August }\end{array}$ \\
\hline Xiushan & 19 July 1971 & 8 October 1971 & 82 & $\begin{array}{l}\text { The severe mid-summer and } \\
\text { autumn drought lasted from July to } \\
\text { September. }\end{array}$ & $\begin{array}{l}\text { Mild in July, moderate in } \\
\text { August and normal in } \\
\text { September }\end{array}$ \\
\hline Chengkou & 27 December 1975 & 15 February 1976 & 51 & $\begin{array}{l}\text { The winter drought lasted for about } \\
60 \text { days from December to February. }\end{array}$ & $\begin{array}{l}\text { Normal from December to } \\
\text { February }\end{array}$ \\
\hline Fengdu & 24 July 1985 & 3 November 1985 & 103 & $\begin{array}{l}\text { The mid-summer and autumn } \\
\text { drought lasted for } 102 \text { days. }\end{array}$ & $\begin{array}{l}\text { Mild in July, normal in } \\
\text { August, mild in September, } \\
\text { normal in the next two } \\
\text { months }\end{array}$ \\
\hline Changshou & 4 August 1990 & 13 October 1990 & 71 & $\begin{array}{l}\text { The severe mid-summer and } \\
\text { autumn drought lasted for } 72 \text { days }\end{array}$ & $\begin{array}{l}\text { Extreme in August, normal in } \\
\text { the next two months }\end{array}$ \\
\hline Shapingba & 26 December 1997 & 8 February 1998 & 45 & $\begin{array}{l}\text { The winter drought occurred from } \\
\text { December to early February. }\end{array}$ & $\begin{array}{l}\text { Mild in December and } \\
\text { January, normal in February }\end{array}$ \\
\hline
\end{tabular}

\footnotetext{
* The start date, the end date, and the duration were identified by using the SWAP index.
}

\subsection{Temporal Evolution of Ordinary Drought Events}

Figure 2 illustrates the temporal variation of annual precipitation, annual duration, and annual severity of ordinary drought events. During the past 56 years, the annual duration extended by 2.5 days (10a) ${ }^{-1}$ and the annual severity intensified by $1.3(10 a)^{-1}$. No significant linear trend and abrupt change were reported at the significance level of $10 \%$. However, the intrinsic fluctuations were obvious. The annual duration ranged from 19 days to 163 days. This range of variation is higher than its multi-year average of 89.9 days. The annual severity varied between 9 and 136 among different years. This wide range is almost two times of the multi-year average of 66.8. The year with high severity and long duration of drought events includes 1961, 1966, 1969, 1978, 1981, 1988, 1992, 2001, and 2012. The annual precipitation is less than the multi-year average of $1155 \mathrm{~mm}$ during all of these drought years. The phenomenon is unsurprising given that insufficient annual precipitation may result in frequent drought events within a specific year, as the SWAP index indicates meteorological drought. From 1960 to 2015, the annual 
precipitation reduced by $10.6 \mathrm{~mm}(10 \mathrm{a})^{-1}$. It is negatively correlated with the annual duration and severity. The linear correlation coefficients are -0.69 and -0.61 , respectively, both of which are significant at the confidence level of $95 \%$. We should, however, notice that annual precipitation is only a rough indicator of the drought extent. For instance, annual precipitation from 2009 to 2013 are almost the same, but the corresponding drought durations and severities were different from each year. This is induced by uneven intraannual distribution and spatial heterogeneity of precipitation within a year.

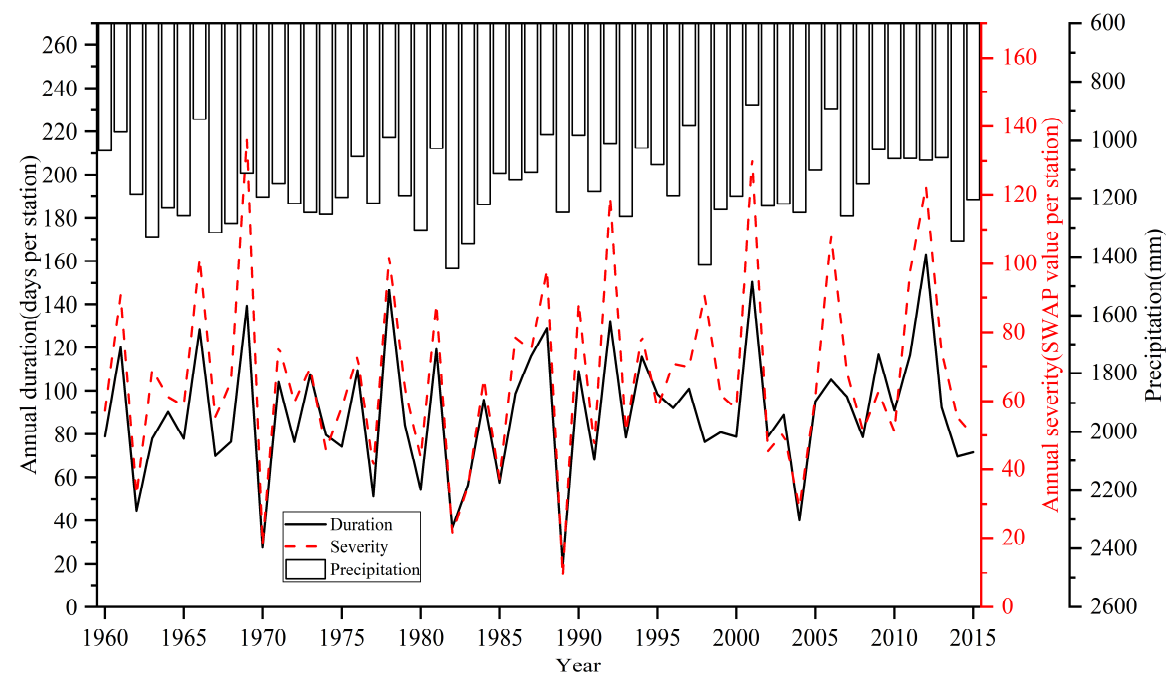

Figure 2. Temporal variation of annual precipitation, annual duration, and annual severity of ordinary drought events in Chongqing (1960-2015).

The decadal variation of drought characteristics is highlighted in Figure 3. The annual duration, severity, and frequency decreased to a valley in the 1980s, and then climbed again until 2010s. During the recent half-decade 2010-2015, the annual duration was 97 days per station, the annual severity reached 73 SWAP value per station, and the frequency of ordinary drought events rose to 73 times and stations.

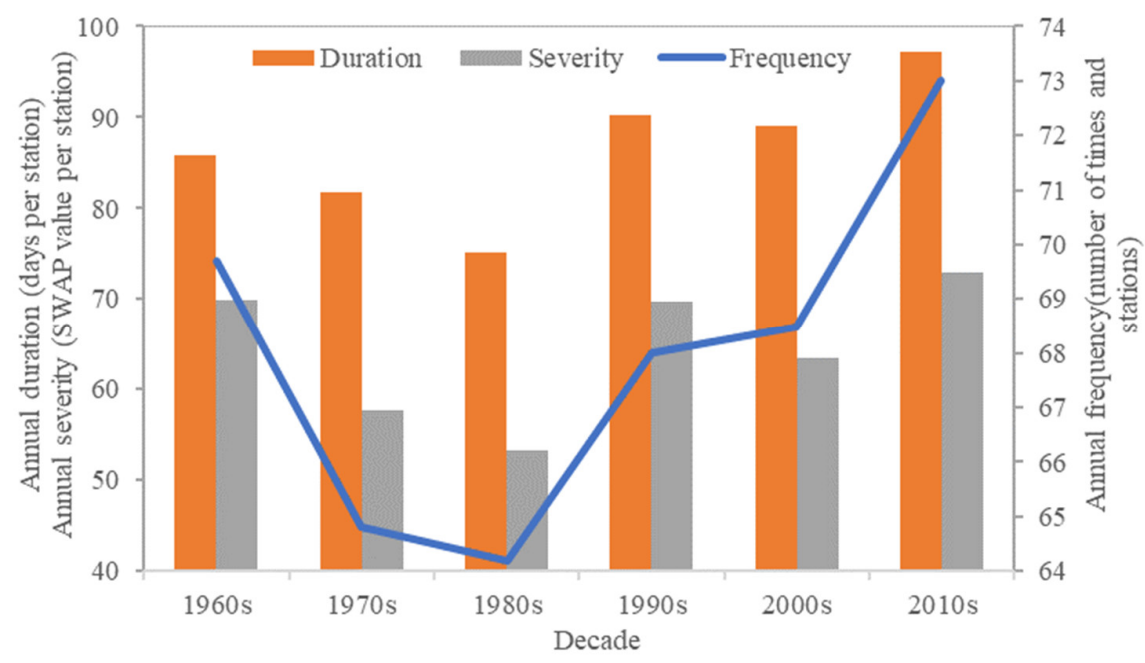

Figure 3. Decadal variation of annual duration, annual severity, and annual frequency of ordinary drought events.

Figure $4 \mathrm{a}-\mathrm{e}$ reflect the spatial distribution of trends in drought duration of ordinary drought events from 1960-2015 to 2000-2015 in Chongqing based on Sen's trend test. The meteorological stations under significant positive trends were $8.8 \%$ for duration in the complete 1960 to 2015 period, concentrated in the western region (Figure 4a). There was an 
overall rise in the duration, but most of them failed the significance test, with the average trend test statistic 0.57. From 1970 to 2015, the middle and southeast regions showed a gradual decrease in the duration and the western region affected by the significant positive trend became more concentrated than the whole period (Figure $4 \mathrm{~b}$ ). The decrease was mainly concentrated in the northeast region from 1980 to 2015 (Figure 4c), while from 1990 to 2015, the decline in the northeast region passed the significance test and most areas of the city showed a decreasing trend, with an average trend test statistic of -0.16 . From 2000 to 2015, there was no significant variation in the duration. The duration in the southeast and middle regions increased slightly, and the areas of the remaining regions that increased and decreased were roughly the same.
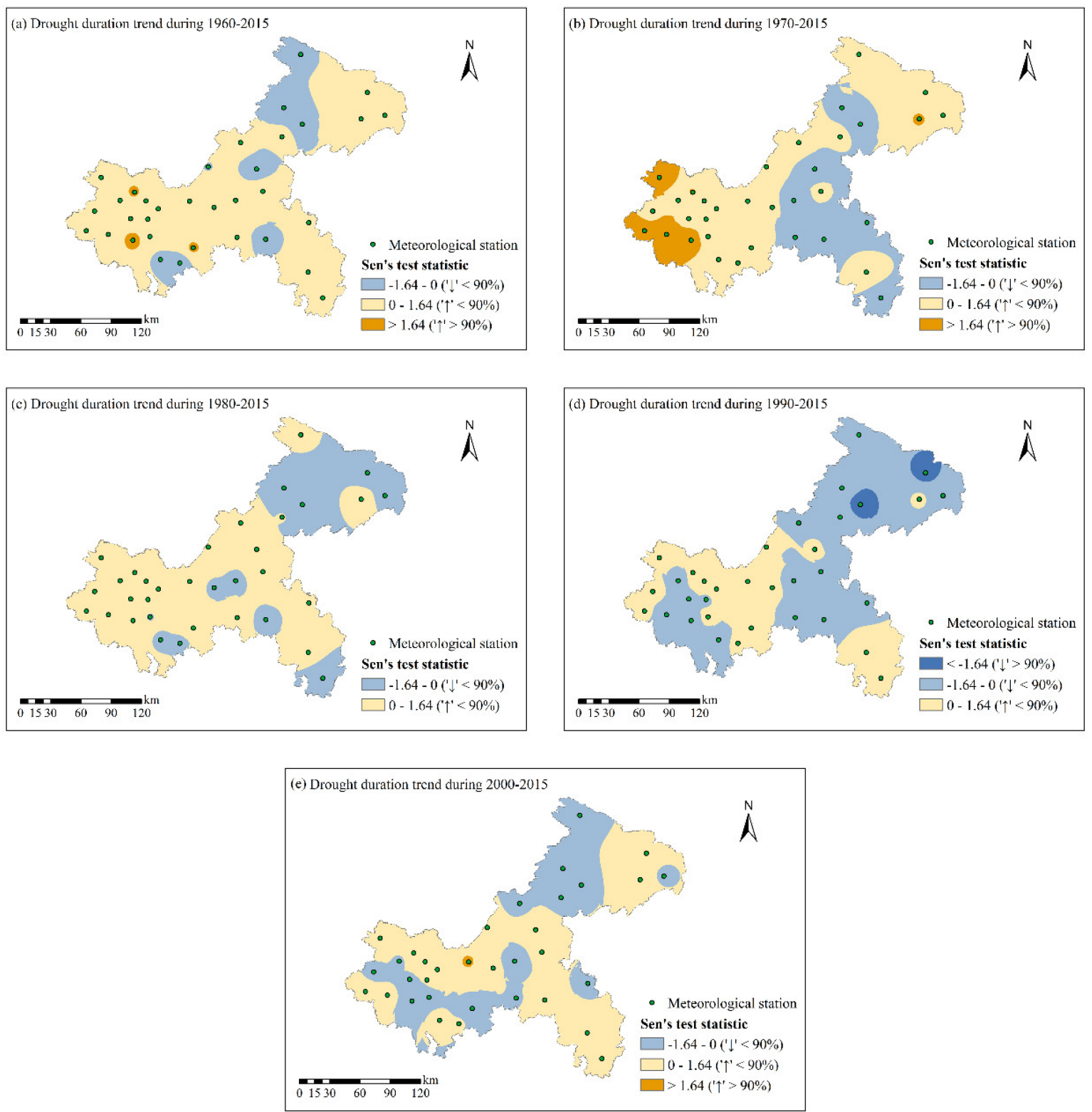

Figure 4. Spatial distribution of trend evolution of annual drought duration for (a) 1960-2015, (b) 1970-2015, (c) 1980-2015, (d) 1990-2015, and (e) 2000-2015 based on Sen's trend test.

Figure 5a-e reflect the spatial distribution of trends in the annual drought severity from 1960-2015 to 2000-2015. The meteorological stations under significant positive trends were $14.7 \%$ for severity in the complete 1960 to 2015 period, more than that for duration, distributed in the western and northeast regions (Figure 5a). From 1970 to 
2015, the increasing trend of severity gradually weakened from northwest to southeast, with an average trend test statistic of 0.63 . The area with decreasing severity was chiefly distributed in the southeast regions (Figure $5 b$ ), while the insignificant increasing trend of severity gradually weakened from west to east from 1980 to 2015, and the decrease was concentrated in the northeast region (Figure 5c). From 1990 to 2015, the reduction was mainly concentrated in the western and eastern parts of Chongqing, with an average trend test statistic of -0.40 (Figure 5d). From 2000 to 2015, there was no significant spatial variation in the severity. The areas with decreasing severity were mainly distributed in the northeast and middle regions (Figure 5e).
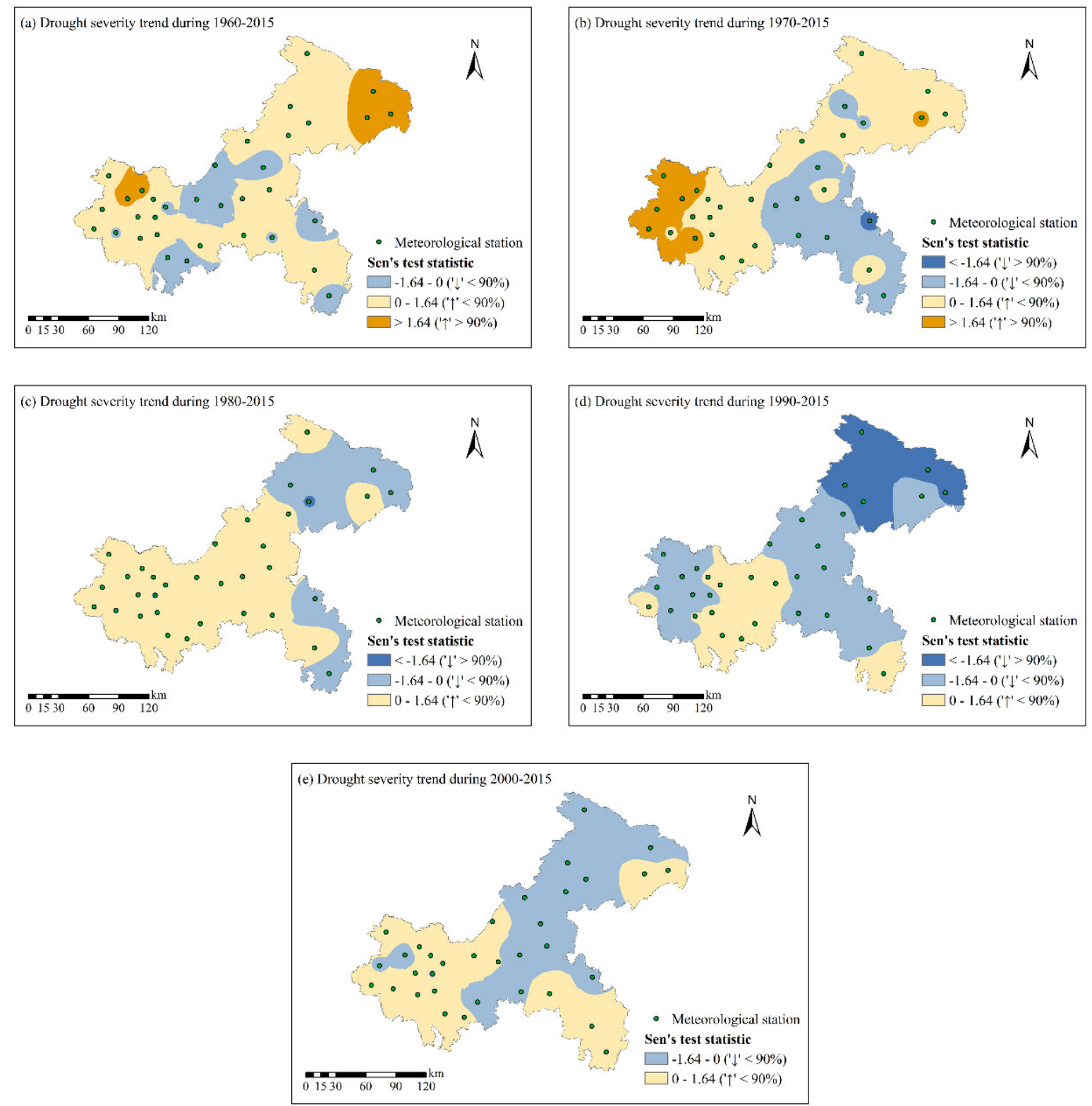

Figure 5. Spatial distribution of trend evolution of annual drought severity for (a) 1960-2015, (b) 1970-2015, (c) 1980-2015, (d) 1990-2015, and (e) 2000-2015 based on Sen's trend test.

The variation of duration and severity from 1990 to 2015 passed the significance test, while the changes during 1980-2015 and 2000-2015 were not significant. On the whole, the spatial variation of annual drought duration and severity was quite inconsistent in different periods. 


\subsection{Characteristics of Drought Events Based on the Duration}

The drought events classified based on duration include ordinary, persistent, and long persistent drought events. Although the annual frequency of ordinary, persistent, and long persistent drought events in each decadal period decreased sharply in turn, the differences in duration and severity of the three drought events were less than that in frequency (Figure 6). Persistent and long persistent drought events occurred less frequently, but their impacts cannot be ignored.

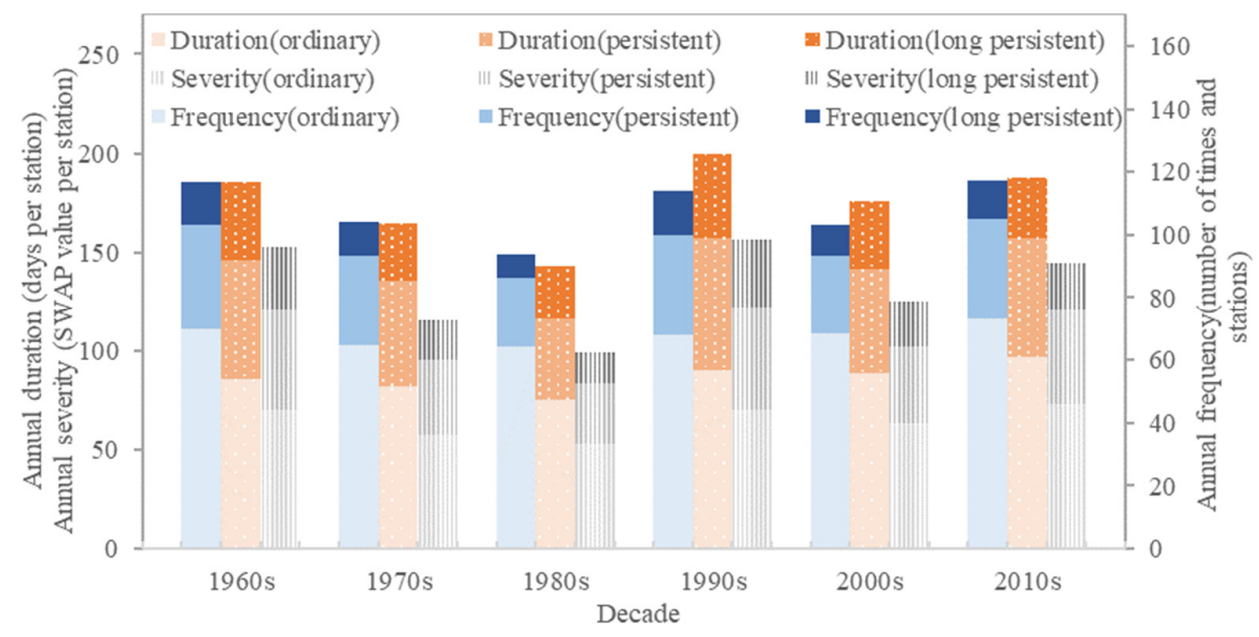

Figure 6. Decadal variation of annual duration, annual severity, and annual frequency of ordinary, persistent, and long persistent drought events.

As for the drought frequency, the three drought events showed a marked downward trend before the 1990s. In the 1980s, the annual frequency of the three drought events all reached the minimums, which were 64.2, 22, and 7.7, respectively. Subsequently, the annual frequency of ordinary drought events increased rapidly, reaching a maximum of 73 in the 2010s. The frequency of persistent and long persistent drought events fluctuated upwards, with the maximum values of 33.3 and 14.2, appearing in the 1960s and 1990s, respectively. The decadal variation of duration and severity of the three drought events was similar to that of drought frequency, which showed a steady decrease prior to the 1990s, and a fluctuating upward tendency since the 1990s. In particular, the annual drought duration of the long persistent drought events from the 2000s (34.7 days per station) to 2010 s (29.9 days per station) decreased. Still, the severity increased slightly from 23.7 to 23.8 per station, indicating that the characteristics of the long persistent drought events in the 2010s changed. Although the duration was slightly shortened, the impact of severity has not diminished.

\subsubsection{Persistent Drought Events}

Table 4 shows the temporal characteristics of annual duration and severity of persistent, long persistent, severe, and extreme drought events in Chongqing. The multi-year average annual duration and severity of persistent drought events were, respectively, 55.6 days and 42.6. The standard deviation of the annual severity was 25.4, indicating that the value was spread out over a widest range among the four types of drought events. The years with a long annual duration and high annual severity of persistent drought events were 1969, 2001, and 1992. The annual duration and severity were significantly negatively correlated with annual precipitation, and the linear correlation coefficients were -0.63 and -0.53 , respectively. Furthermore, at the significance level of $10 \%$, there was no significant linear trend and abrupt change in persistent, long persistent, severe, and extreme drought events. The intrinsic fluctuations were severe. 
Table 4. The temporal characteristics of annual duration and severity of persistent, long persistent, severe, and extreme drought events from 1960 to 2015.

\begin{tabular}{|c|c|c|c|c|}
\hline Types of Drought Events & Persistent & Long Persistent & Severe & Extreme \\
\hline $\begin{array}{l}\text { Multi-year average annual duration } \\
\text { (days per station) }\end{array}$ & 55.6 & 102.9 & 54.7 & 12.4 \\
\hline $\begin{array}{l}\text { Multi-year average annual severity } \\
\text { (SWAP value per station) }\end{array}$ & 42.6 & 25.0 & 47.5 & 12.7 \\
\hline $\begin{array}{l}\text { Standard deviation of annual duration } \\
\text { (days per station) }\end{array}$ & 30.3 & 38.6 & 15.0 & 13.6 \\
\hline $\begin{array}{l}\text { Standard deviation of annual severity } \\
\text { (SWAP value per station) }\end{array}$ & 25.4 & 23.3 & 17.5 & 15.3 \\
\hline Years with long annual duration & $1969,2001,1992$ & $2006,1981,1986$ & $1969,2001,1990$ & 1969, 1990, 2006 \\
\hline Years with high annual severity & $1969,2001,1992$ & $1969,2006,2001$ & $1969,1992,2006$ & $1969,1998,2006$ \\
\hline $\begin{array}{l}\text { Linear correlation coefficient between } \\
\text { annual precipitation and } \\
\text { annual duration }\end{array}$ & $-0.63 *$ & $-0.38^{*}$ & -0.50 * & $-0.40 *$ \\
\hline $\begin{array}{c}\text { Linear correlation coefficient between } \\
\text { annual precipitation and } \\
\text { annual severity }\end{array}$ & $-0.53 *$ & $-0.43^{*}$ & $-0.46 *$ & $-0.33 *$ \\
\hline
\end{tabular}

* The linear correlation coefficient was statistically significant at the confidence level of $95 \%$.

The duration and severity of persistent drought events in Chongqing showed an insignificant decrease in most parts of the middle and southeast regions, and an increase in the western and northeast regions (Figure 7). Three and one meteorological stations in the western and northeast regions passed the significance test, which showed that their duration and severity increased significantly, and the degree of persistent drought events strengthened.
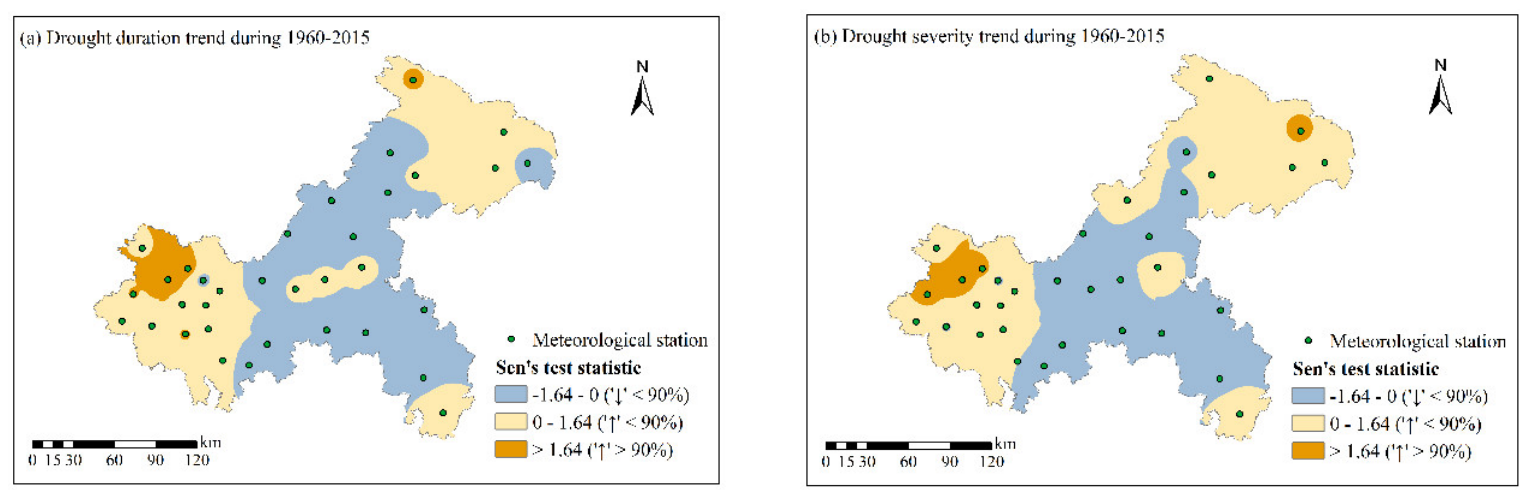

Figure 7. Spatial trend evolution of annual drought duration (a) and drought severity (b) of persistent drought events from 1960 to 2015.

\subsubsection{Long Persistent Drought Events}

The multi-year average annual duration and severity of long persistent drought events were 102.9 days and 25 (Table 4). Regarding the standard deviation of annual duration, despite the greatest value for long persistence drought events, which was 38.6 days, it is worth noting that the value for persistent drought events was similarly large, since both values were approximately twice as high as those for severe and extreme drought events. Comparably, the standard deviation of annual severity for persistent and long persistent drought events were also much larger than the values for the remaining two types. The annual duration and severity fluctuated more wildly for persistent and long persistent drought events comparing to severe and extreme drought events. The years with long duration were 2006, 1981, and 1986, and the most severe long persistent drought events 
occurred in 1969, 2006, and 2001. The annual duration and severity were significantly negatively correlated with annual precipitation, with linear correlation coefficients of -0.38 and -0.43 , respectively.

The duration and severity showed a decreasing trend in the middle and southeast regions (Figure 8). Among them, the duration of the two meteorological stations in the middle region showed a significant decreasing trend, and the degree of drought was alleviated. Similar to the persistent droughts, the duration and severity increased in the western and northeast regions. The difference was that the duration and severity of long persistent drought events only increased significantly in the northeastern part of the northeast region, and the degree of drought intensified.
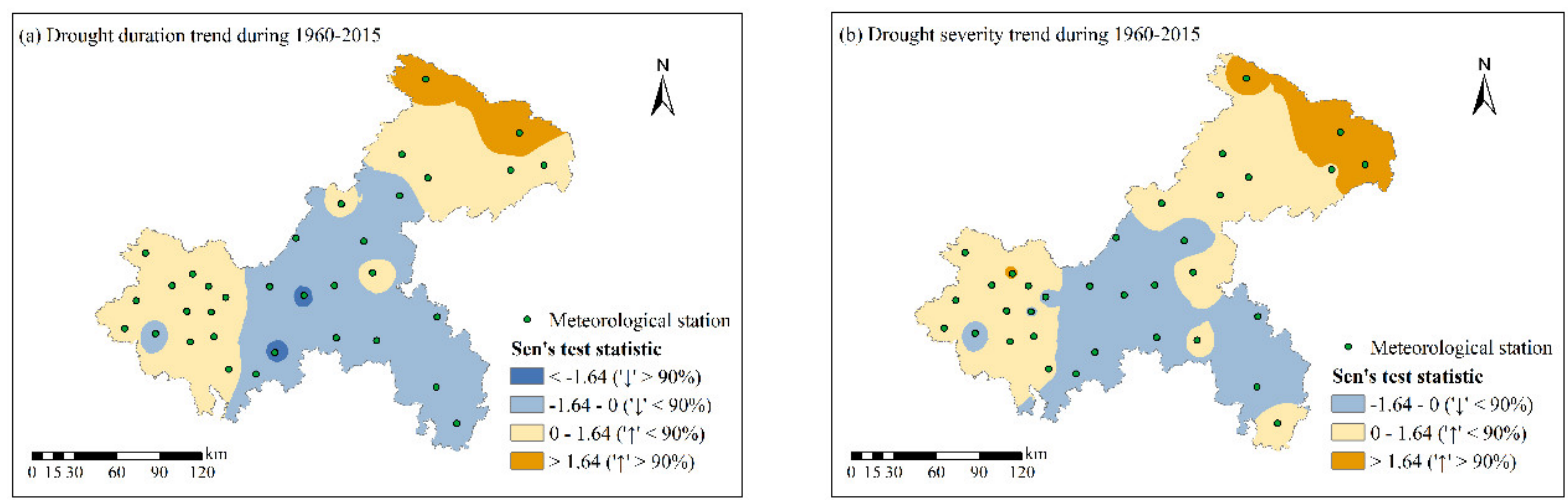

Figure 8. Spatial trend evolution of annual drought duration (a) and drought severity (b) of long persistent drought events from 1960 to 2015.

\subsection{Characteristics of Drought Events Based on the Magnitude}

The drought events classified based on magnitude include ordinary, severe, and extreme drought events. The annual frequency of ordinary, severe, and extreme drought events in each decadal period decreased sharply in turn, similar to the duration and severity (Figure 9).

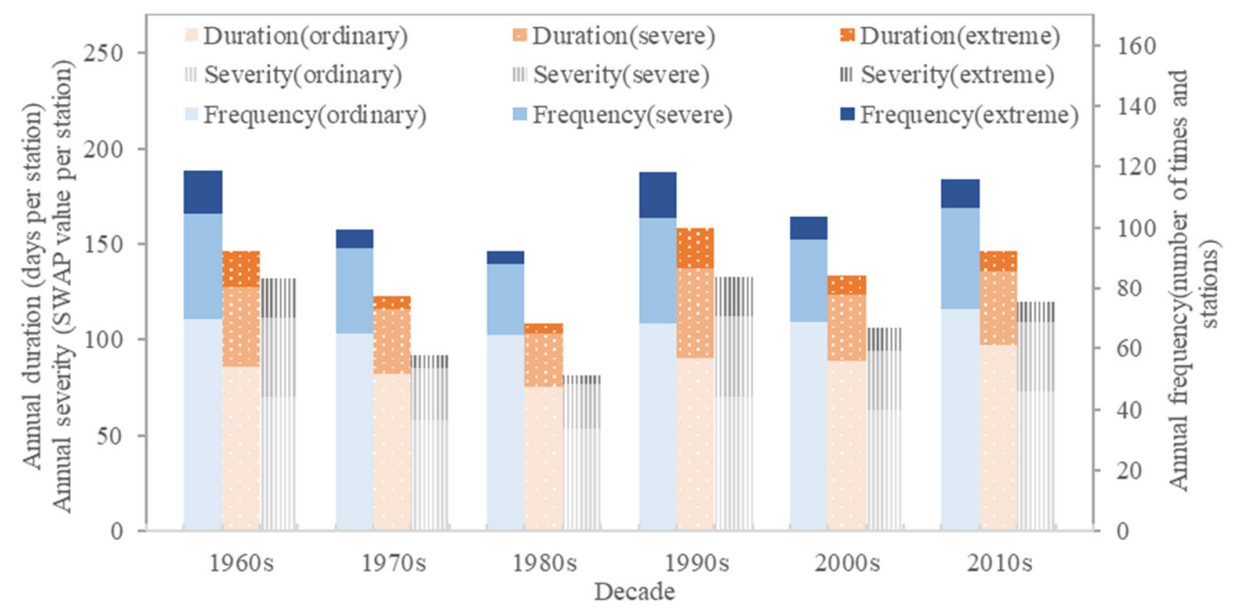

Figure 9. Decadal variation of annual duration, annual severity, and annual frequency of ordinary, severe, and extreme drought events.

As for the drought frequency, the three drought events showed a marked downward trend before the 1990s. Subsequently, the annual frequency fluctuated upwards. The annual frequency of severe droughts was high in the 1990s, 1960s, and 2010s-35.2, 34.6, and 33.5, respectively. Extreme droughts also occurred more frequently in these three periods, with an annual frequency of 15.2,14.4, and 9.3. The decadal variation of duration and severity of the three drought events was similar to that of drought frequency, which showed a steady 
decrease from the 1960s to 1980s, and a fluctuating upward trend from the 1990s to 2010s. However, there were differences between different drought events. To illustrate this, the duration and severity of severe drought events increased from the 2000s to 2010s, but those of extreme events decreased. The increase in the impact of severe drought was higher than that of extreme drought from the 2000s to 2010s. The composition characteristics of drought events have changed.

\subsubsection{Severe Drought Events}

The multi-year average duration and severity of severe drought events were 57.4 days and 47.5 (Table 4). The years with long duration of severe drought events were 1969, 2001, and 1990, and the most serious severe drought events took place in 1969, 1992, and 2006. The annual precipitation was negatively correlated with the annual duration and severity. The linear correlation coefficients were -0.50 and -0.46 , respectively, both of which were significant at the confidence level of $95 \%$.

The duration and severity of severe drought events in Chongqing showed a decreasing trend in the middle and southeast regions (Figure 10). In the western and northeast regions, the duration and severity increased, and the stations with a significant increase were mainly distributed in the western region.
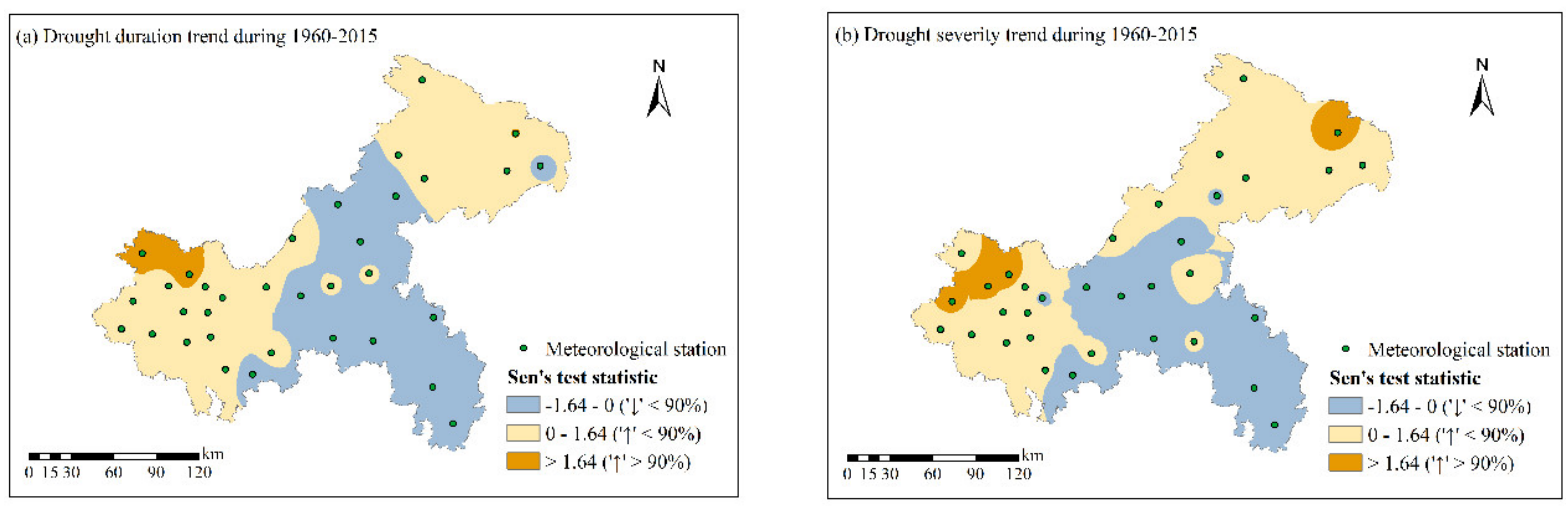

Figure 10. Spatial trend evolution of annual drought duration (a) and drought severity (b) of severe drought events from 1960 to 2015.

\subsubsection{Extreme Drought Events}

The multi-year average annual duration and severity of extreme drought events were 12.4 days and 12.7, respectively (Table 4 ). The years with a long duration and high severity were 1969 and 2006. The duration was long, and the severity was low in 1990, contrary to that in 1998. The annual duration and severity of extreme drought events were significantly negatively correlated with annual precipitation, with linear correlation coefficients of -0.40 and -0.33 , respectively.

The duration and severity of extreme drought events showed an insignificant increase in most parts of the western and northeast regions of Chongqing (Figure 11), and they declined insignificantly in parts of the western, middle, and southeast regions. The area where the duration and severity of extreme drought events showed an insignificant decreasing trend was smaller than that of other drought events.

The main urban area of Chongqing is located in the western region, with a large population and high population density (Figure 1). With the continuous improvement of industries in the western region, the population flows into Bishan, Jiangjin, Yongchuan, and other districts around the main urban area, increasing water vulnerability. Moreover, the duration and severity of persistent, long persistent, severe, and extreme drought events in the western region increased insignificantly from 1960 to 2015. Urban water supply projects need to consider coping with these variations. There are many mountainous areas in the northeast region of Chongqing, and the population and population density are moderate (Figure 1). When planning the construction scale of rural drinking water projects 
in mountainous areas, the evolution of the duration and severity of meteorological drought events in the northeast region should be considered.
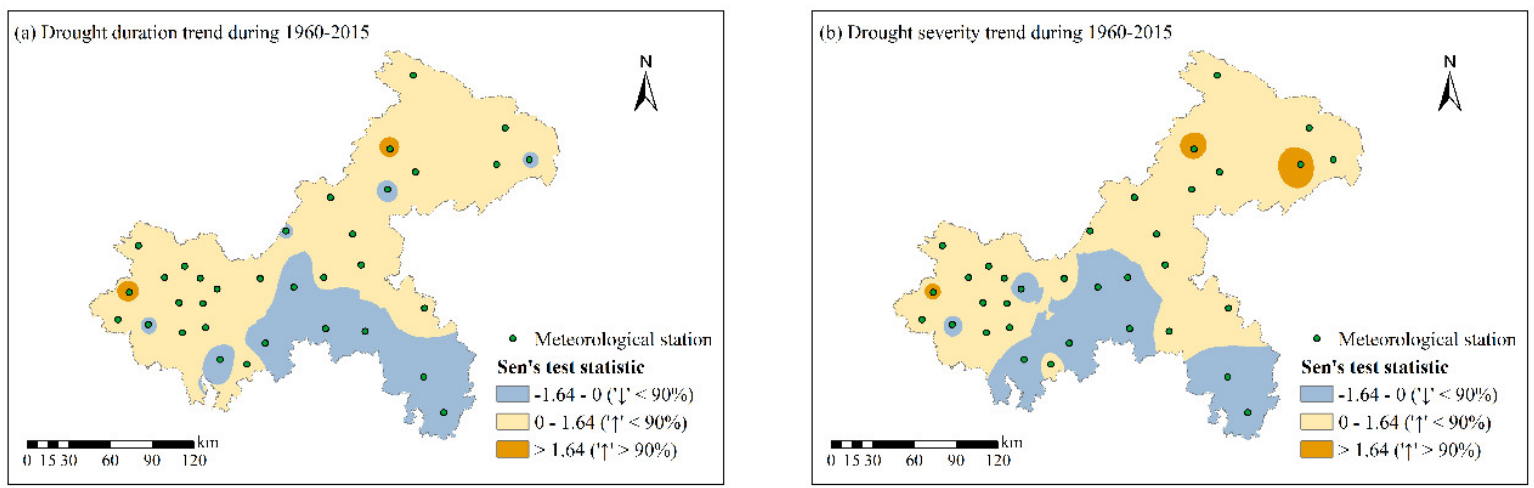

Figure 11. Spatial trend evolution of annual drought duration (a) and drought severity (b) of extreme drought events from 1960 to 2015.

\subsection{Discussion}

Understanding the driving forces of the inter-annual variability of meteorological droughts is critical for the reliable projection and effective mitigation of drought hazards. Generally speaking, the climate system in Chongqing, southwest China, is jointly controlled by two subtropical monsoons, one of which comes from the west Pacific Ocean and the other comes from the north Indian Ocean. The extent of floods and droughts are usually manipulated by the strength of these two distinct monsoons as well as influenced by diverge landforms and land uses. To exactly identify and simulate the coupled relationship between droughts, climate and land surfaces remain a big challenge in this area [31]. Accordingly, several studies have explored the causes of meteorological droughts by the use of climatic indexes. For example, Zhang et al. [32] indicated that the droughts over southwest China become worse when the sea surface temperature (SST) anomalies affected by El Niño occur further west and intensify. Wang et al. [33] found that Atlantic oscillation and sunspots can explain the variability of droughts well. Xiang et al. [34] claimed that ENSO was also responsible for the variability of droughts in southwest China. Specifically, El Niño and La Niña have an asymmetric influence on summer precipitation in the following year over Chongqing. There is a close connection between typical flood years in summer over Chongqing and El Niño events. However, the typical drought years in summer of Chongqing are not significantly related to La Niña [34].

Insufficient precipitation is the direct cause of meteorological droughts. Using the precipitation observation data, the SWAP can accurately identify drought events. We found that the monthly SPI index was sensitive to identify monthly scale drought. However, it would break up a real persistent drought event into a few fragments of sub-events. The daily SWAP index can identify 10-day scale drought events better than the SPI.

Considering the rainfall runoff and hydrological infrastructure, the runoff may be analyzed to study the hydrological drought and the propagation of meteorological drought to hydrological drought, which may effectively assist the water resources management departments in formulating corresponding policies to ensure water safety. Furthermore, the drought-flood abrupt alternation events occur frequently in Chongqing, southwest China. Further improvement of the SWAP may accurately characterize the drought-flood abrupt alternation events.

\section{Conclusions}

The premise of drought risk management is to capture the spatiotemporal evolution of meteorological drought events. This study used the daily SWAP index and multi-threshold run theory to identify and characterize droughts in Chongqing, China. The modified Sen's 
trend test and the Pettitt test were applied to analyze properties of ordinary, persistent, long persistent, severe, and extreme droughts. The following conclusions can be drawn:

1. The SWAP is capable of identifying meteorological drought events. Combined with the multi-threshold run theory, it can effectively determine the onset, duration, and severity of drought events, which is consistent with the historical records.

2. There was no significant linear trend and abrupt change in annual duration and severity of drought events in Chongqing from 1960 to 2015, but the fluctuations were severe. Such wild fluctuations are still a big challenge to drought response and has practical significance. There existed prominent decadal variations. Annual frequency, duration, and severity of drought events showed a steady decreasing trend before the 1990s, and then fluctuated upward. The annual duration and severity of drought events were significantly negatively correlated with annual precipitation.

3. The spatial variation of the duration and severity of ordinary drought events was quite different among distinct periods. The annual drought duration and severity decreased from 1990 to 2015 but increased from 1960 to 2015 as a whole. In the whole study period 1960-2015, the duration and severity of persistent, long persistent, severe, and extreme drought events declined insignificantly in most parts of the middle and southeast regions but increased in the western and northeast regions.

Author Contributions: Conceptualization, B.L. and Y.L.; data curation, Y.L. and C.L.; formal analysis, B.L. and Y.L.; investigation, B.L. and C.L.; methodology, B.L., Y.L. and W.W.; software, Y.L.; supervision, B.L. and W.W.; validation, B.L.; visualization, Y.L.; writing—original draft, Y.L.; writing—review and editing, B.L. and W.W. All authors have read and approved the final manuscript.

Funding: The study was supported by the National Key Research and Development Program of China (No. 2018YFC0407900) and the National Natural Science Fund of China (No. 41701015).

Institutional Review Board Statement: Not applicable.

Informed Consent Statement: Not applicable.

Data Availability Statement: Restrictions apply to the availability of these data. Data was obtained from the National Climate Center of the China Meteorological Administration and are available at http:/ / data.cma.cn (accessed on 16 December 2020) with the permission of the National Climate Center of the China Meteorological Administration.

Acknowledgments: The authors wish to thank the National Climate Center of the China Meteorological Administration for providing the daily rainfall data.

Conflicts of Interest: The authors declare no conflict of interest.

\section{References}

1. Wilhite, D.A.; Glantz, M.H. Understanding the drought phenomenon: The role of definitions. Water Int. 1985, 10, 111-120. [CrossRef]

2. Wilhite, D.A. Drought as a Natural Hazard: Concepts and Definitions; Drought: A Global Assessment; Routledge: London, UK, 2000; Volume 1, pp. 3-18.

3. World Meteorological Organization (WMO). Drought Monitoring and Early Warning: Concepts, Progress and Future Challenges; WMO: Geneva, Switzerland, 2006; p. 1006.

4. Wilhite, D.A. Managing drought risk in a changing climate. Clim. Res. 2016, 70, 99-102. [CrossRef]

5. Palmer, W.C. Meteorological Drought, Technique Report No. 45; U.S. Department of Commerce Weather Bureau Research: Washington, DC, USA, 1965.

6. Mckee, T.B.; Doesken, N.J.; Kleist, J. The relationship of drought frequency and duration to time scales. In Proceedings of the 8th Conference on Applied Climatology, Anaheim, CA, USA, 17-22 January 1993; pp. 179-184.

7. Vicente-Serrano, S.M.; Begueria, S.; Lopez-Moreno, J. A Multiscalar Drought Index Sensitive to Global Warming: The Standardized Precipitation Evapotranspiration Index. J. Clim. 2010, 23, 1696-1718. [CrossRef]

8. Wu, H.; Hayes, M.J.; Weiss, A.; Hu, Q. An evaluation of the Standardized Precipitation Index, the China-Z Index and the statistical Z-Score. Int. J. Clim. 2001, 21, 745-758. [CrossRef]

9. Myronidis, D.; Fotakis, D.; Ioannou, K.; Sgouropoulou, K. Comparison of ten notable meteorological drought indices on tracking the effect of drought on streamflow. Hydrol. Sci. J. 2018, 63, 2005-2019. [CrossRef] 
10. Kim, D.; Byun, H.; Choi, K.S. Evaluation, modification, and application of the Effective Drought Index to 200-Year drought climatology of Seoul, Korea. J. Hydrol. 2009, 378, 1-12. [CrossRef]

11. Morid, S.; Smakhtin, V.; Moghaddasi, M. Comparison of seven meteorological indices for drought monitoring in Iran. Int. J. Clim. 2006, 26, 971-985. [CrossRef]

12. Raude, J.M.; Wambua, R.M.; Mutua, B.M. Detection of Spatial, Temporal and Trend of Meteorological Drought Using Standardized Precipitation Index (SPI) and Effective Drought Index (EDI) in the Upper Tana River Basin, Kenya. Open J. Mod. Hydrol. 2018, 8, 83-100.

13. Deo, R.C.; Byun, H.R.; Adamowski, J.F.; Begum, K. Application of effective drought index for quantification of meteorological drought events: A case study in Australia. Theor. Appl. Climatol. 2016, 128, 359-379. [CrossRef]

14. Lu, E. Determining the start, duration, and strength of flood and drought with daily precipitation: Rationale. Geophys. Res. Lett. 2009, 36. [CrossRef]

15. Lu, E.; Luo, Y.; Zhang, R.; Wu, Q.; Liu, L. Regional atmospheric anomalies responsible for the 2009-2010 severe drought in China. J. Geophys. Res. Atmos. 2011, 116. [CrossRef]

16. Lu, E.; Cai, W.; Jiang, Z.; Zhang, Q.; Zhang, C.; Higgins, R.W.; Halpert, M.S. The day-to-day monitoring of the 2011 severe drought in China. Clim. Dynam. 2014, 43,1-9. [CrossRef]

17. Zhao, Y.; Weng, Z.; Chen, H.; Yang, J. Analysis of the Evolution of Drought, Flood, and Drought-Flood Abrupt Alternation Events under Climate Change Using the Daily SWAP Index. Water 2020, 12, 1969. [CrossRef]

18. Wang, G.; Li, J.; Deng, L.; He, M. China meteorological data sharing service system: Design and development. J. Meteorol. Res. 2004, S1, 10-16.

19. Yevjevich, V. An Objective Approach to Definitions and Investigations of Continental Hydrologic Droughts; Hydrologic Papers; Colorado State University Publisher: Fort Collins, CO, USA, 1967.

20. Moyé, L.A.; Kapadia, A.S. Predictions of drought length extreme order statistics using run theory. J. Hydrol. 1995, 169, 95-110. [CrossRef]

21. Shiau, J.T. Fitting Drought Duration and Severity with Two-Dimensional Copulas. Water Resour. Manag. 2006, 20, 795-815. [CrossRef]

22. He, J.; Yang, X.; Li, J.; Jin, J.; Wei, Y.; Chen, X.J. Spatiotemporal variation of meteorological droughts based on the daily comprehensive drought index in the Haihe River basin, China. Nat. Hazards 2014, 75, 199-217. [CrossRef]

23. Wen, K.G. China Meteorological Disaster Canon: Chongqing Volume; China Meteorological Press: Beijing, China, 2008; ISBN 978-7-5029-4459-9. (In Chinese)

24. Sen, Z. Innovative trend significance test and applications. Throe. Appl. Climatol. 2017, 127, 939-947. [CrossRef]

25. Sen, Z. Innovative Trend Analysis Methodology. J. Hydron. Eng. 2012, 17, 1042-1046. [CrossRef]

26. Sen, Z. Trend Identification Simulation and Application. J. Hydrol. Eng. 2014, 19, 635-642. [CrossRef]

27. Tosunoglu, F.; Kisi, O. Trend Analysis of Maximum Hydrologic Drought Variables Using Mann Kendall and Şen's Innovative Trend Method. River Res. Appl. 2017, 33, 597-610. [CrossRef]

28. Wang, W.; Zhu, Y.; Liu, B.; Chen, Y.; Zhao, X. Innovative Variance Corrected Sen's Trend Test on Persistent Hydrometeorological Data. Water 2019, 11, 2119. [CrossRef]

29. Pettitt, A.N. A Non-Parametric Approach to the Change-Point Problem. Appl. Statist. 1979, 28, 126-135. [CrossRef]

30. Myronidis, D.; Theofanous, N. Changes in climatic patterns and tourism and their concomitant effect on drinking water transfers into the Region of South Aegean, Greece. Stoch. Environ. Res. Risk. Assess. 2021, 1-15. [CrossRef] [PubMed]

31. Liu, M.; Xu, X.; Sun, A. Decreasing spatial variability in precipitation extremes in southwestern China and the local/large-scale influencing factors. J. Geophys. Res. Atmos. 2015, 120, 6480-6488. [CrossRef]

32. Zhang, W.; Jin, F.; Zhao, J.; Ren, H. The Possible Influence of a Nonconventional El Niño on the Severe Autumn Drought of 2009 in Southwest China. J. Clim. 2013, 26, 8392-8405. [CrossRef]

33. Wang, P.; Wu, X.; Hao, Y.; Wu, C.; Zhang, J. Is Southwest China drying or wetting? Spatiotemporal patterns and potential causes. Theor. Appl. Climatol. 2020, 139, 1-15. [CrossRef]

34. Xiang, B.; Zhou, J.; Li, Y. Asymmetric relationships between El Niño/La Niña and floods/droughts in the following summer over Chongqing, China. Atmos. Oceanic Sci. Lett. 2020, 13, 171-178. [CrossRef] 